\title{
REPLICAS IN CULTURAL HERITAGE: 3D PRINTING AND THE MUSEUM EXPERIENCE
}

\author{
M. Ballarin ${ }^{1 *}$, C. Balletti ${ }^{1}$, P. Vernier ${ }^{1}$ \\ ${ }^{1}$ Laboratorio di Fotogrammetria, Università Iuav di Venezia, Santa Croce 191, 30135 Venezia (martinab, balletti, vernier)@iuav.it
}

\author{
Commission II, WG II/8
}

KEY WORDS: 3D printing, Museum, Cultural Heritage, Replicas, Modelling, 3D acquisition

\begin{abstract}
:
3D printing has seen a recent massive diffusion for several applications, not least the field of Cultural Heritage. Being used for different purposes, such as study, analysis, conservation or access in museum exhibitions, 3D printed replicas need to undergo a process of validation also in terms of metrical precision and accuracy.

The Laboratory of Photogrammetry of Iuav University of Venice has started several collaborations with Italian museum institutions firstly for the digital acquisition and then for the physical reproduction of objects of historical and artistic interest. The aim of the research is to analyse the metric characteristics of the printed model in relation to the original data, and to optimize the process that from the survey leads to the physical representation of an object. In fact, this could be acquired through different methodologies that have different precisions (multi-image photogrammetry, TOF laser scanner, triangulation based laser scanner), and it always involves a long processing phase. It should not be forgotten that the digital data have to undergo a series of simplifications, which, on one hand, eliminate the noise introduced by the acquisition process, but on the other one, they can lead to discrepancies between the physical copy and the original geometry. In this paper we will show the results obtained on a small archaeological find that was acquired and reproduced for a museum exhibition intended for blind and partially sighted people.
\end{abstract}

\section{INTRODUCTION}

\subsection{The diffusion of 3D printing in the Geomatic world}

The recent technological evolution has seen a massive diffusion on the global market of solid printing. In recent years, the advent of 3D printing has opened new scenarios and new possibilities in the production of commonly used objects, especially since the costs of these machines have significantly lowered, making these tools available to a wider audience. At a professional level, it has had a great impact for example in the design field. Here, this technology has opened the way for numerous designers and artists who have started taking advantage of $3 \mathrm{D}$ printers in order to create products to be placed directly on the market. In fact, this type of technology has an enormous creative and technological potential.

In the Geomatics world, the physical representation of an object often starts from a point cloud and passes through a digital model. This path contains three steps that imply a different way of representing an object. These three representations have different purposes and consequently different characteristics. The point cloud model is part of the surveying world. It is acquired through photogrammetric, laser scanning and topographic techniques, which are strictly connected to a way of representing reality linked to the concepts of precision and accuracy. Through these methodologies we obtain numerical data that imitate the shape of an object and that always guarantee a metric control on the reliability of the result.

The purpose of digital and physical models is different, as they both are traditionally linked to the concept of usability of an object. They allow the user to view reality in a clear and immediate way, in particular where it is no longer directly accessible. Some examples may be the virtual anastylosis of a collapsed building, or applications designed to allow a direct contact with the object, which is often prohibited, especially in the field of Cultural Heritage (see, for example, Arbace et al., 2013; Santopuli et al., 2010).

In architecture, these models are usually the result of two different processes. The first one involves the creation of closed surfaces by joining together the vertices of the point cloud, with different methodologies. The second one is a process of interpretation, which passes through CAD software products, where the quasi-continuity of the detected data is discretized into a series of lines that represent just the elements necessary to characterize its architectural structure. This transition from a type of representation by points (which we can call a numerical model) to a type of representation by lines or surfaces (for example a mathematical CAD model) up to a physical representation often implies very long data processing.

The numerical data is often redundant compared to the purposes of the final model, both in terms of the amount of data acquired and in terms of precision and accuracy (Bitelli et al., 2017). On the other hand, we often deal with numerical models in which some significant parts for the description of the monument are missing. Protrusions or undercuts on the objects could cause this phenomenon on the point cloud model.

Nonetheless, surveying is an essential requirement for knowing and representing the shape and geometry of an object, in terms of dimensions and proportions of its parts. Therefore, it is necessary for a faithful reproduction of an object, regardless of its shape.

\subsection{D printing in museums}

This rapid diffusion has also had consequences in the field of Cultural Heritage, and in particular in museums. The most

\footnotetext{
* Corresponding author
} 
avant-garde institutions are beginning to recognize in modern technologies a means to add new "reading" methods to the most traditional visit paths (Wilson et al., 2017, Petrelli 2013, Dudley 2010). In fact, the focus is shifting from the museum visit as we understand it, towards a multi-layered and multi-sensorial experience: more and more, modern museums place supports that allow new ways of interaction next to the works of art exhibited in traditional display cases. Monitors, projections, physical replicas add information, but also they modify the way in which the user approaches the artwork itself.

Our way of experiencing reality passes through all the senses we have at our disposal. The museum as a vehicle of knowledge cannot fail to take this aspect into consideration (Mc Ginnis 2014; Sportun 2014).

Particular attention has been given to haptic senses, through the creation of touchable exhibition, and handling sessions that enable the user to personally interact with the object they are looking at.

While recent studies have demonstrated that this is an easier way for people to learn and experience reality (Neumüller et al. 2014a), it becomes compulsory when objects are used for didactic purposes (i.e. to involve children in the learning process) or for allowing access to blind and partially sighted people.

And it is not just about handling and touching objects. The association between printed copies and other kind of media enable us to overcome the traditional "static nature" of the physical model, which confines the objects to a specific historical moment.

The Laboratory of Photogrammetry itself, together with the research group "Visualizing Venice", has worked for an exhibition at Palazzo Ducale, using, among others, projections on three dimensional printed models to tell the stories of the lagoon and some of its islands (Galeazzo 2017; Balletti et al., 2016; Calabi, Galeazzo, 2015).

In this way, we managed to show non-expert people the historical transformations of the city, using 3D printed models and $3 \mathrm{D}$ video mapping. In fact, combining these two means, we were able to overcome the concept of the $3 \mathrm{D}$ model as a "frozen representation" that shows a precise moment in time and to provide the experience of witnessing the continuous flow of history. This was particularly true in the case of the island of San Secondo, for which we created three 3D models showing three different moments in time, with a project of video projection mapping that turned "the surfaces into a dynamic video display" (Balletti et al., 2016).

Moreover, nowadays we are witnessing an attempt to add information to the physical object, creating "sensorized" models. Among a great number of 3D copies produced just for display purposes (Scopigno et al., 2017; Scopigno et al., 2014; Allard et al., 2005; Neumüller et al. 2014b), literature shows us many examples of integration between 3D printed copies and touch sensors or buttons to better explore objects, visualize them in monitors and tell their stories (Balletti et al., 2017; D’Agnano et al. 2015; Capurro et al., 2014).

In this context, solid printing acquires added value compared to the simple mass production objects, which have made their way into the global market.

However, another distinction has to be done. On one side there are printed models whose final purpose is to provide a new and more in-depth modality to obtain a more accurate knowledge of the world, especially in a context - the museum - in which the tactile exploration is often precluded. On the other side there are printed models that are used for scientific purposes, such as study, analysis and conservation of archaeological findings or works of art.
The first ones are used to better access and enjoy exhibitions. Therefore, the most important aspects to be considered are realism and likelihood, that involve the material used for 3D printing, its colour, but also the weight of the object and its texture and touch feeling.

Otherwise, if the object is reproduced for scientific purposes, then it has to be the perfect copy of the original in every single part. If the aim is to replace an existing object with a strong historical-artistic value, one must inevitably consider the problem of the construction of digital models to be printed on one side and the conformity of the copy to the original on the other.

\section{THE CASE STUDY}

\subsection{Purpose of the survey}

The object analysed is an archaeological finding of the upper Palaeolithic (11.600 years B.P.) named "Uomo barbuto di Vado all'Arancio" (Bearded mad of Vado all'Arancio). It is an engraved limestone slab found near Massa Marittima (GR) (Martini 2016). On the main face we can still see his nose, his eye, his long moustache, his straight and thin mouth, his beard and what could be his hair or a headgear. On the opposite side, there are still traces of what could have been another human face, but the drawing looks unfinished (figg. 1-2). The size of the object is very small: its dimensions are $8.2 \times 4.1 \times 1.1 \mathrm{~cm}$.

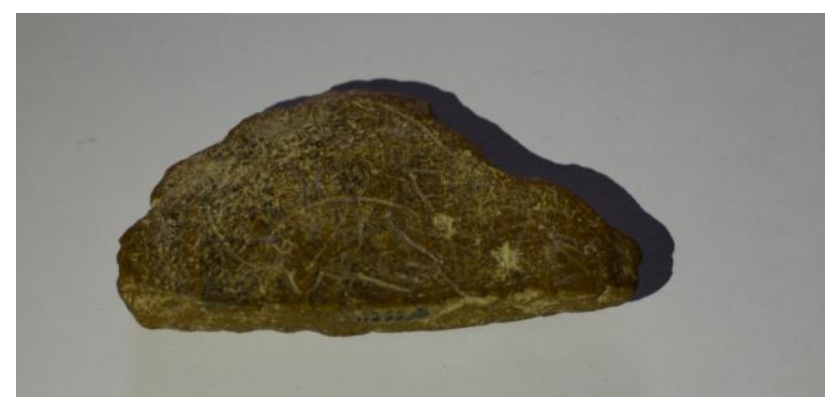

Figure 1: Uomo barbuto di Vado all'arancio

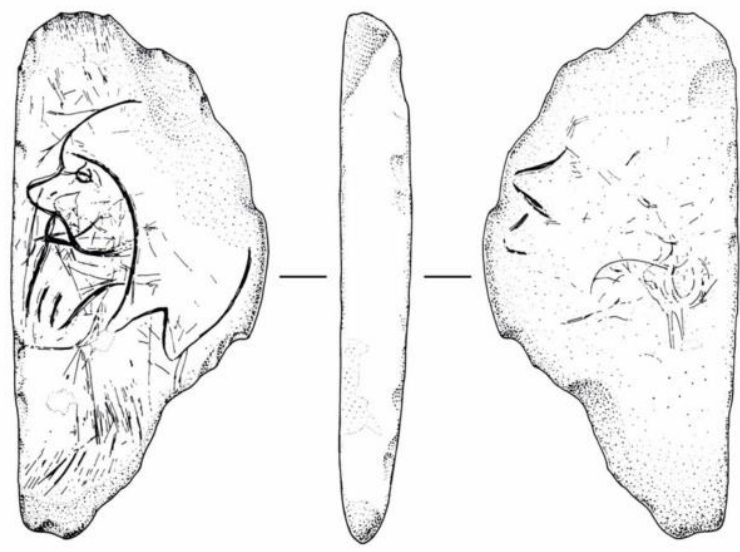

Figure 2: Drawings of the limestone slab (after Martini 2016)

The project was carried out in collaboration with the Archaeological Museum of Massa Marittima, where the object is held, and its purpose was the production of a path accessible to blind or partially sighted people through audio-tactile works. 


\subsection{Data acquisition and processing}

Because of the small size of the object, we decided to use a triangulation based laser scanner with projection of a laser light blade (Range 7, Konika Minolta) that allows us reaching the best precision among the ones we have at the Laboratory of Photogrammetry. This instrument guarantees a sub-millimetric precision (up to $40 \mu \mathrm{m}$ ), it can be used with two different lenses, tele and wide-angle, and it allows the acquisition of small object from a distance of between 450 and $800 \mathrm{~mm}$. According to the type of lens mounted on the instrument, the size of the acquisition area can vary from $79 \times 99 \mathrm{~mm}$ to $267 \times 334 \mathrm{~mm}$, on the XY plane.

For this case study, we used a tele lens: as already stated, the object was very small and the engravings on its surface were so light they could barely be perceived by touching it. In order to acquire these small deformations of the surface, we had to obtain the highest resolution.

Before starting the acquisition phase, the instrument was calibrated, reaching a precision on calibration of $9 \mu \mathrm{m}$. This was necessary also to avoid possible consequences caused by travel shocks and vibration or deformations (such as thermal expansion) caused by temperature changes.

The object was acquired through 23 scans, taken at an approximate distance of 700-800 $\mathrm{mm}$. For each scan, a manual focus was used, clicking on a central point of the object. The high number of scans was due to the necessity of guaranteeing a high overlapping among data for their subsequent orientation, and to the limit of the tele lens, which has a small depth of field (fig. 3).

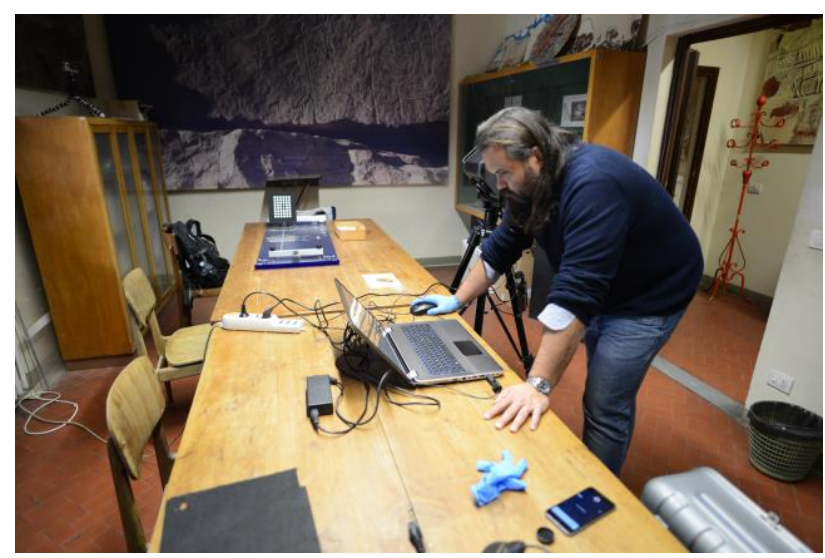

Figure 3: Acquisition field

A first rough alignment performed still at the museum (with the software Range Viewer) allowed us to check the coverage of the entire object and to be sure no important data were missing.

Subsequently, the 23 scans underwent the standard processing pipeline, using the software Geomagic Studio (Geomagic):

- first, each scan was cleaned and we deleted the marginal parts, which are mostly affected by noise;

- then, we refined the registration through a global alignment (average distance: $0.251 \mathrm{~mm}$; standard deviation: 0.474 $\mathrm{mm})$;

- we merged the scans into a single file, removing the redundant parts;

- in the end, we filled the small holes that were left.

The operations of hole closure were made only for the smaller holes and it was not particularly time consuming, as the number of scans and the object geometry (that do not have undercuts) allowed us the acquisition of an almost complete digital model.
At the end of data processing, the model was composed by approximately 1 million triangles, therefore we did not need to decimate it. In fact, the $3 \mathrm{D}$ printer management software products usually do not allow to work with models made by a high number of triangles (often working with over a million triangles is a problem). The small dimensions of the object allowed the acquisition of a low number of triangles: therefore, we did not need to simplify its geometry by applying decimation algorithms. In our opinion, the choice of this type of object constituted an added value to the analyzes that were carried out.

\subsection{D printing}

The digital models realised were then printed using an online printing service: Sculpteo (Sculpteo). This is one of many websites that give the possibility to upload a 3D model designed by the user, get it printed by a wide range of 3D printers, techniques and materials, and get it delivered at home by express delivery in any part of the world. The website also offers a consulting service that helps non-expert users producing optimal models for printing.

The presence and growth of these kinds of services demonstrate the diffusion of solid printing in the market. Even if 3D printers are by now quite cheap and affordable, nowadays, users do not even need to buy one. They just need to upload their models on the internet and wait for the delivery.

Using this website, we decided to test different printers and materials, as we wanted to see which one gave the best results. In fact, as stated before, if a replica has to be used in a museum context, it is clear that it has to feel similar to the real objects, in terms of weight, texture and general appearance. Checking the results of different printers and materials is therefore compulsory.

We printed four test copies: three with the same machine but using three different materials; the fourth one with another printer that allows the creation of fully coloured replicas.

The technique chosen is Selective Laser Sintering (SLS): it is a technique which uses a laser as a sintering source of a thermoplastic powder: thin layers of dust of different materials, such as polycarbonate, nylon, ABS, are laid down progressively and consolidated, where necessary, by the laser. The succession of layers is guaranteed by the descent of the plate on which the object lies (usually they are displacements in the order of tenths of millimetres). This type of printing does not need supports, because the object and its protrusions are supported by the same powder that has not been consolidated. At the end of the process, the prototype is freed from excess dust using compressed air guns and subsequent sandblasting (Balletti et al., 2017; Gibson et al., 2015; Scopigno et al., 2014).

The two white copies were printed with a EOS Formiga P395 using a plastic material (Nylon).

The first one (fig. 4) is Nylon PA 12, created from a fine polyamide powder and available in different colour. Depending on the wall thickness, this material can be both solid and flexible: if the walls are $0.8 \mathrm{~mm}$ (minimum), the final object will be flexible; it they are $2 \mathrm{~mm}$ (minimum) it will be rigid.

We chose a layer thickness, among the ones available (100/150 $-60 \mu \mathrm{m})$, that allowed us to obtain a good resolution also for the smallest details $(100 \mu \mathrm{m})$.

The second one (fig. 5) was printed in Nylon 3200 Glass-filled (glass-filled nylon), which is made of a mix of polyamide powder and glass beads. The surface of the material is white and slightly polished. For this reason, the replica could not be used for further analyses, as the laser beam of Range 7 passed through the surface and could not acquire any data. 


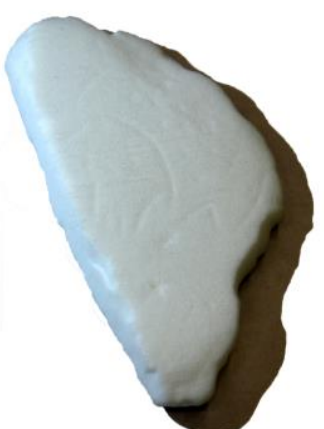

Figure 4: Nylon PA 12

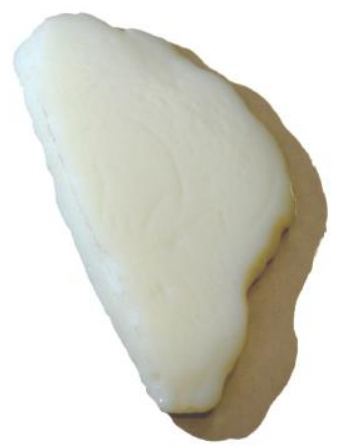

Figure 5: Nylon Glass-filled

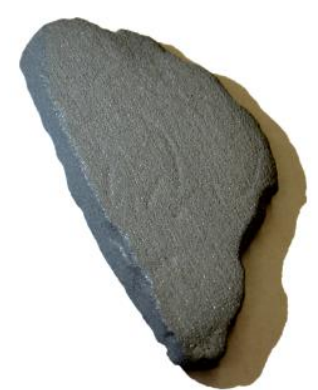

Figure 6: Alumide

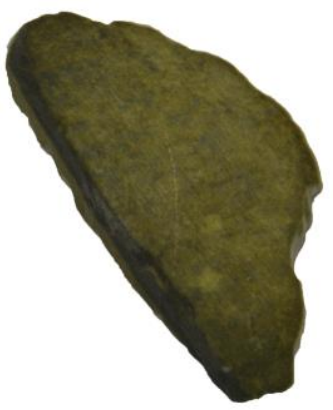

Figure 7: Coloured replica
The grey copy (fig. 6) is made of alumide: a mix of polyamide powder and fine aluminium particles, which gives the final product a shiny look. There is only one resolution available for this material as the smallest layer thickness is $150 \mu \mathrm{m}$.

The fourth replica (fig. 7) was realized with a ZPrinter 650 s by 3D Systems, that uses a fine powder, similar to sandstone, which is painted during the printing process. The original file uploaded must then be composed by both geometrical shape of the object and texture and colour information.

This machine can print in 390,000 different colours and it is easier and cheaper than other methods, such as the application of a coloured film on the replica or direct brush painting on the surface, even if it often does not guarantee the same quality on the results (Rivola et al., 2016).

The website itself guarantees a good result, but warn the users the product could have small differences between the colours of the real object and the ones of the replicas, especially for blacks and fresh colours.

Maximum resolution available with this printer is $100 \mu \mathrm{m}$, while they guarantee the correct reproduction of details that have a minimum size of $0.4 \mathrm{~mm}$.

\section{4 "Augmented" 3D printing}

As the final aim was the access of the object also for blind people inside a museum exhibition and as the surface shows some engravings that are just visible to human eyes but cannot be felt by touching it, we decided to create a sort of "augmented" printed model.

The digital .stl file was imported into Mudbox (Mudbox), a software by Autodesk for digital sculpting and painting. Here, we used a texturized model (obtained by applying one of the photos that were captured during surveying) as a guideline to increase the depth of the model where we could see the signs of engraving. In this way, we were able to produce a 3D replica also adequate for handling sessions (fig. 8).

This replica was not used for further analyses as its metrical accuracy was already compromised by the realization process itself.
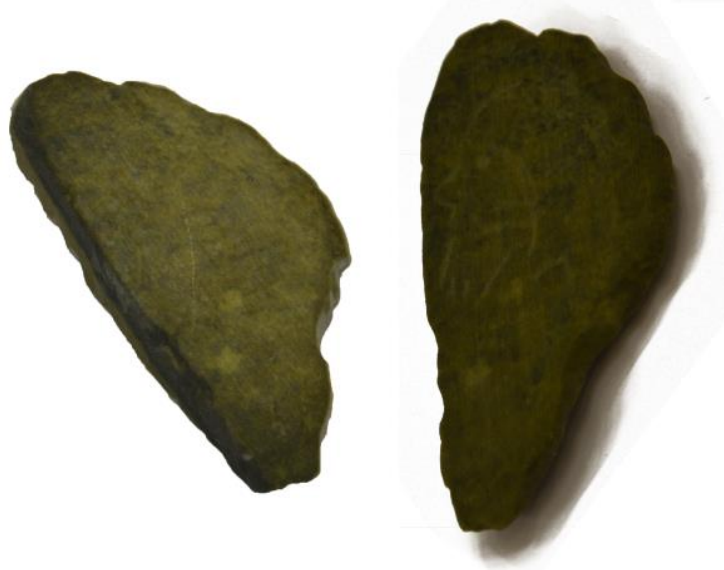

Figure 8: Comparison between the coloured 3D replica and the "augmented" one. 


\section{ANALYSES}

As already stated, purpose of this research was the analysis of the printed replicas not just from a "figurative" point of view, in terms of aesthetic quality of the result, but also from a metric point of view, in terms of precision of the final product.

We decided to analyse all the replicas produced, also those created by the same printer, in order to check the reliability of the test itself and the behaviours of different materials.

\subsection{Data acquisition}

The acquisition process followed the same pipeline used for the original object.

The instrument used was the triangulation based laser scanner Range 7, with the tele lens described above. In order to guarantee the same precision on the acquisition and to control the thermal expansion, the instrument was calibrated again (precision: $9 \mu \mathrm{m}$ ).

What changed was the number of scans and the use of a rotating stage, that speeded up the acquisition time also performing an automatic first rough alignment. This system uses an auto focus, but we believed it would not have had any significant effects on the final model. In fact, already during the acquisition of the original object, we saw that both methods guaranteed the recording of suitable data for the purposes, considering both the depth of field and the number of scans acquired.

The acquisition and processing phases were kept unchanged for all three objects. Therefore, for sake of clarity, we will describe the process carried out on a single object, specifying instead from time to time the statistical indices obtained for the different alignments.

For every object, we acquired three sets of data:

1) 12 scans (setting the movement of the rotating stage to a $30^{\circ}$ angular step) placing the object leaning on its side,

2) 6 scans (angular step of $60^{\circ}$ ) with its main side facing up;

3) 6 scans (angular step of $60^{\circ}$ ) with its main side facing down. In this way, we were able to acquire data with the right focus on the entire object.

Given the complex data acquisition, the processing phase was more difficult than the one carried out on the original object, but we tried to keep the workflow as unaltered as possible. Therefore, we decided to first process the three datasets separately and subsequently align and merge them.

For every dataset, each single scan was first cleaned, then realigned. The precision on the alignment of the single scans for each one of the three datasets was good for all the replicas: we obtained an average distance of approximately $0.03 \mathrm{~mm}$ with a standard deviation of $0.04 \mathrm{~mm}$. After the alignment, the scans were merged into a single mesh, obtaining three data for each replica.

The three meshes obtained were aligned together into the same coordinate system. The noisiest parts were then deleted in order to keep just the best data for each part of the object. The precision in this second alignment had different results: the monochromatic replicas showed an average distance of 0.03 mm with a standard deviation of $0.07 \mathrm{~mm}$; the coloured one showed an average distance of $0.07 \mathrm{~mm}$ with a standard deviation of $0.10 \mathrm{~mm}$.

As with the original object, because of its geometry and the high number of scans, we did not need to perform a long post processing phase. There were just a few small holes we had to fill and there was no need to decimate the meshes.

\subsection{Comparisons}

The digital data of three printed objects acquired were then compared to the one that was used for 3D printing.

The module used for the analysis of the two data sets is contained within the alignment menu of Geomagic Studio (Geomagic), which uses the same ICP algorithm used for the orientation of the scans, and it allows displaying a series of basic information for analysis: the maximum distance between two comparable points in the two meshes, the average distance and the standard deviation.

The two models obtained by the acquisition of the monochromatic printings show comparable results (table 1):

\begin{tabular}{|c|c|c|}
\hline & Grey Nylon & White Nylon \\
\hline Maximum distance $(\mathrm{mm})$ & 0.276 & 0.352 \\
\hline Average distance $(\mathrm{mm})$ & 0.035 & 0.046 \\
\hline Standard deviation $(\mathrm{mm})$ & 0.036 & 0.044 \\
\hline
\end{tabular}

Table 1: Statistical indices obtained from the comparisons of the first two replicas

A part from some small differences between the two comparisons, probably caused by global alignments, the data are concordant. As we can see from figures 9 and 10, the flat areas are more precise compared to the most complex ones. An interesting thing to note is the difference on the engraved parts: in the printed models they appear less deep, which is a clear sign of the decreasing of precision in $3 \mathrm{D}$ printing.

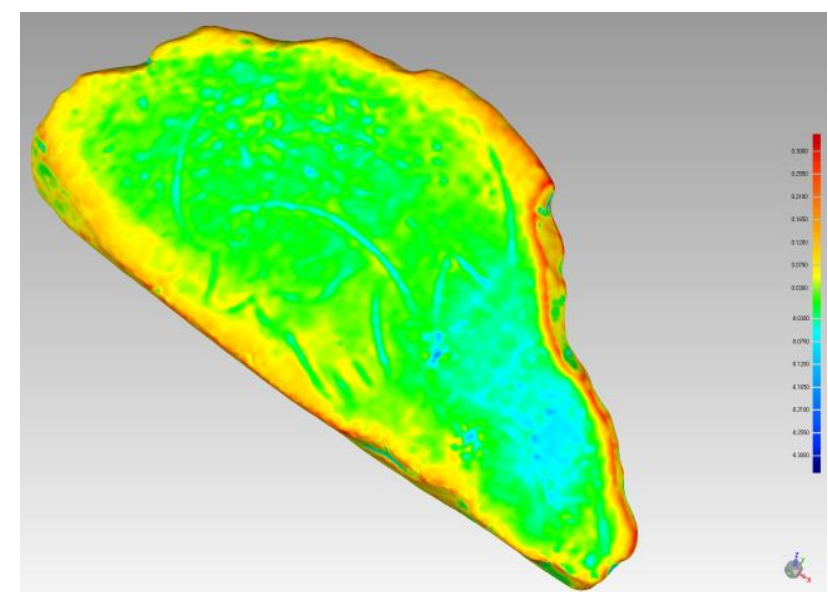

Figure 9: Results on the Nylon PA 12

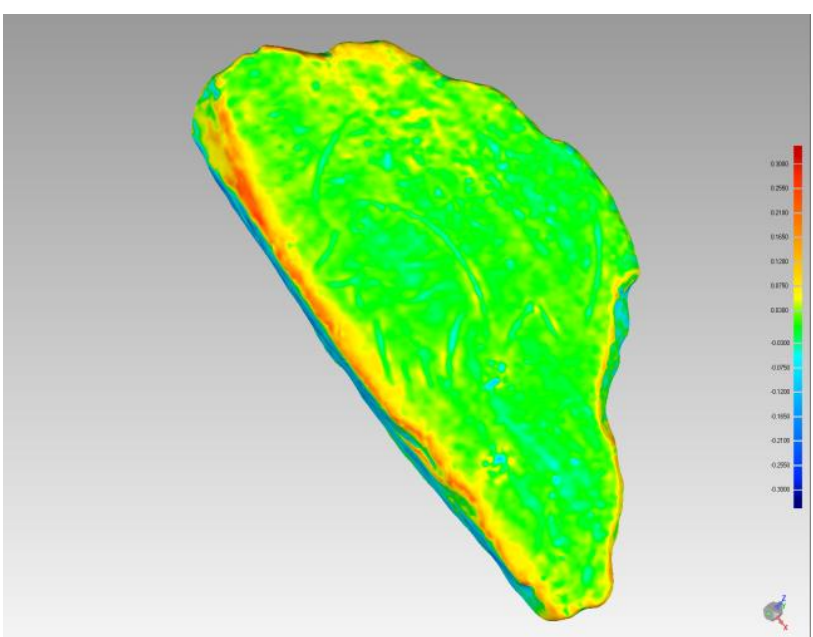

Figure 10 : Results on the alumide 
On the other hand, the one printed with the multicolour printer shows an average distance nearly one order of magnitude higher than the other ones (table 2):

\begin{tabular}{|c|c|c|}
\hline & Grey Nylon & Coloured \\
\hline Maximum distance $(\mathrm{mm})$ & 0.276 & 0.400 \\
\hline Average distance $(\mathrm{mm})$ & 0.035 & 0.096 \\
\hline Standard deviation $(\mathrm{mm})$ & 0.036 & 0.065 \\
\hline
\end{tabular}

Table 2: Statistical indices obtained from the comparisons of the grey nylon replica and the coloured one
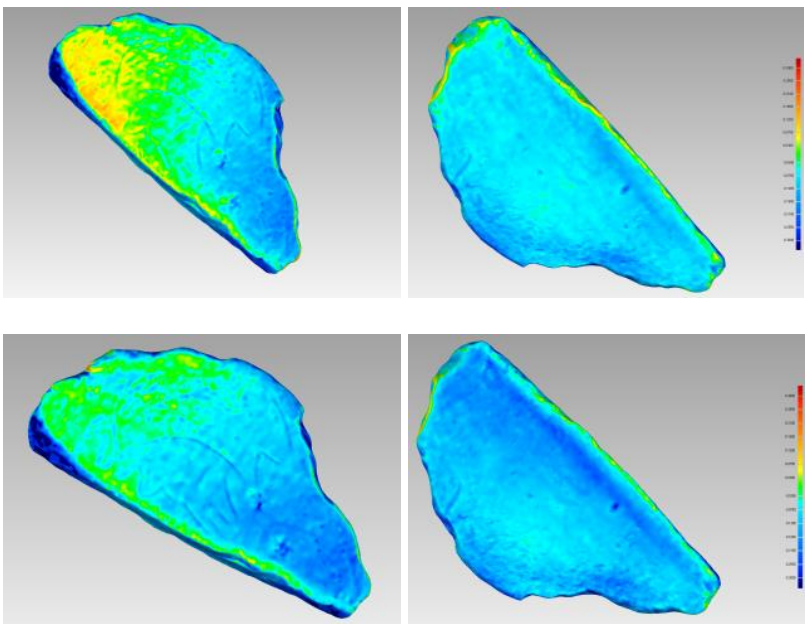

Figure 11: Results on the coloured replica. Above: the first test; below: the second one.

In order to be certain of the results, we performed another acquisition of the coloured printed object. In this way were able to discard possible causes of imprecision, such as the variation of the instrument temperature and a non-correct alignment of the single scans.

Although with small differences, this second test confirmed the over-all results of the first one (fig. 11). The printed model appears generally bigger than the original one, probably caused by the printing process itself. In fact, the printer first creates a uniform layer of powder and then it colours it with another head. This two processes could easily lead to the creation of a slightly bigger model. Quoting the website: "The print itself is carried out layer by layer. A rolling batch leaves a uniform layer of the sandstone-like powder. From there two printing heads pass over the batch, coloring and adhering the object at the same time. The batch of powder then makes another pass, until the object is completed" (Sculpteo Multicolor Material).

\section{CONCLUSIONS}

In Cultural Heritage, 3D printing technologies have opened a wide range of new possibilities both in terms of museum access, and in terms of cataloguing and study, providing the basis for visualization on the one hand and the analysis of shape and geometry on the other. One of the advantages of $3 \mathrm{D}$ printing is a high flexibility compared to the traditional process that leads to physical reproductions. For example, before producing the physical copy, the digital representation can be edited, scaled, modified: its geometry could be altered in any possible way. Replicas also have the advantage of being touchable without damaging the conservative state of the original object, thus providing a new way of interacting with the objects of art and therefore learning from them.
Precisely because of this dual nature of the copy, which is used for informational as well as scientific purposes, it must be realized taking into account a series of factors: on the one hand the realism and the verisimilitude of the reproduced object, which must have texture, weight and appearance coherent with the original, on the other the adherence of the shape, which is expressed, in the Geomatics world, with the terms of precision and accuracy of the printed model. Moreover, if solid printing has become one of the possible products of a metric survey alongside the traditional representations in orthogonal projection - the analysis of the process that from the acquisition of the metric data leads to the creation of the digital model that has to be printed becomes compulsory.

Within this process, techniques and methods of data acquisition and processing can lead to a loss of adherence of the copy to the original. Firstly, there are different precisions of the acquisition systems, which, depending on the technique used, lead to the formation of a point cloud that moves away from the real object already in the acquisition phase.

Subsequently, data processing uses filters that, while leading to the optimization of the model for printing or display, also lead to a change in the geometry of the copy. The main ones are decimation and smoothing, which are often inevitable processes: the metric data acquired through photogrammetry or laser scanning is frequently redundant with respect to the purposes of physical reproduction and usually very noisy. From time to time we must make choices based on the evaluation of the number of points (and consequently the size of polygons) and on the filters to be applied for the elimination of noise, in relation to the quality of the final model.

This question is linked to another aspect related to the adherence of the model to reality: what is the form of modelling that allows a greater mimesis of the real object? Surface models created by triangulation allow to obtain meshes based entirely on the points clouds acquired. However, the processes described above lead the triangular mesh to never maintain the accuracy of the initial model. On the other hand, even if these operations remove the digital model from the real one, they still are inevitable steps to obtain a qualitatively good copy. On the contrary, solid models constructed using graphic primitives are also very far from the real object, because they are the result of an interpretation.

In this paper, we chose to focus on the last step of the process: the one related to the precision of printers. In fact, the comparisons were made between the digital model of the printed object and the original one after the optimization for printing. However, beyond the precision of the instrument used and the alignment of the scans, no post processing was carried out through the application of filters. For this reason, the object was considered an ideal application case for these analyses. Moreover, its dimensions allowed to work on a 1:1 scale.

In our opinion, from the tests described above the discrepancy between verisimilitude and metric precision is evident: the coloured object is certainly much closer to reality from a qualitative and descriptive point of view, but from a metric point of view it is the one that presents greater deviations from the original geometry.

The precisions obtained are comparable with other tests previously developed by the Photogrammetry Laboratory (see for example Balletti et al., 2017). Further analyses are currently under way on objects of different typologies and scales (e.g. statues or architectural monuments) always in a museum perspective. In order to analyse not only the accuracy of the printing, but also to validate the process that leads to the formation of the digital model, different acquisition techniques and different elaborations methods will be compared. 


\section{ACKNOWLEDGEMENTS}

This work has been carried out under the GAMHer project: Geomatics Data Acquisition and Management for Landscape and Built Heritage in a European Perspective, PRIN: Progetti di Ricerca di Rilevante Interesse Nazionale - Bando 2015, Prot. 2015HJLS7E.

\section{REFERENCES}

Allard T. T.; Sitchon M. L.; Sawatzky R.; Hoppa R. D. (2005): Use of Hand-held Laser Scanning and 3D Printing for Creation of a Museum Exhibit. In: M. Mudge, N. Ryan and R. Scopigno (eds.), The $6^{\text {th }}$ International Symposium on Virtual Reality, Archaeology and Cultural Heritage: Proceeding, Pisa, Eurographic Association, pp. 182-196.

Arbace L.; Sonnino E.; Callieri M.; Dellepiane M.; Fabbri M.; Idelson A. I.; Scopigno R. (2013): Innovative uses of 3d digital technologies to assist the restoration of a fragmented terracotta statue. In: Journal of Cultural Heritage 14, 4, pp. $332-345$.

Balletti C.; Ballarin M.; Guerra F. (2017): 3D Printing: State of the Art and Future Perspectives. In: Journal of Cultural Heritage, 26, pp. 172-182.

Balletti C.; Galeazzo L.; Gottardi C.; Guerra F.; Vernier P. (2016): New technologies applied to the history of the Venice Lagoon. In E. Livieratos (ed.), Digital Approaches to Cartographic Heritage, Proceedings of the 11th ICA Conference, Thessaloniki, CartoGeoLab-Laboratory of Cartography \& Geographic Analysis, 2016, pp. 182-190. ISNN 2459-3893.

Bitelli G.; Balletti C.; Brumana R.; Barazzetti L.; D’Urso M.G.; Rinaudo F.; Tucci G. (2017): Metric Documentation of Cultural Heritage: Research Directions from the Italian GAMHER Project. In: The International Archives of the Photogrammetry, Remote Sensing and Spatial Information Sciences, Volume XLII-2/W5, 2017, 26th International CIPA Symposium 2017, 28 August-01 September 2017, Ottawa, Canada, pp. 83-90.

Calabi, D., Galeazzo, L. (eds.) (2015). Acqua e cibo a Venezia. Storie della laguna e della città. Venezia, Marsilio.

Cappurro C.; Nollet D.; Pletinckx D. (2014): Tangible Interfaces for Digital Museum Applications: The Virtex and Virtex Light Systems in the Keys to Rome Exhibition. In: G. Guidi, R. Scopigno, J. C. Torres and H. Grafs (eds.), Proceedings of the 2015 Digital Heritage International Congress, New York, Springer.

D’Agnano F.; Balletti C.; Guerra F.; Vernier P. (2015): Tooteko: a Case Study of Augmented Reality for an Accessible Cultural Heritage, Digitization, 3D printing and Sensors for an Audio-tactile Experience. In: The International Archives of the Photogrammetry, Remote Sensing and Spatial Information Sciences, Volume XL-5/W4, 2015, 3D Virtual Reconstruction and Visualization of Complex Architectures, 25-27 February 2015, Avila, Spain, pp. 207-2013.

Dudley I. (2010): Three-dimensional Model of an Ancient Egyptian Falcon Mummy Skeleton. In: Rapid Prototyping Journal, 21, pp. 368-372.
Galeazzo L. (2017): Mapping Change and Motion in the Lagoon: the island of San Secondo. In: K. L. Huffman, A. Giordano and C. Bruzelius (eds.), Visualizing Venice: Mapping and Modeling Time and Change in a City, London, Routledge, 2017, pp. 43-50. ISBN 978-11-3828-599-6.

Gibson I.; Rosen D.; Stucker B. (2015): Additive Manufacrturing Technologies: 3D Printing, Rapid Prototyping, and Direct Digital Manufacturing, New York, Springer Science+Business Media. ISBN: 9781493921126.

Martini F. (2016): L'arte paleolitica e mesolitica in Italia, Millenni. Studi di archeologia preistorica, 12, Firenze.

McGinnis R. (2014): Islands of Stimulation: Perspectives on the Museum Experience, Present and Future. In: N. Levent and A. Pascual-Leone (eds.), The Multisensory Museum: Crossdisciplinary Perspectives on Touch, Sound, Smell, Memory, and Space, Plymouth, Roman \& Littlefield, pp. 319-329 ISBN: 9780810895355 .

Neumüller M.; Reichinger A.; Florian R.; Kern C. (2014a): 3D Printing for Cultural Heritage: Preservation, Accessibility, Research and Education. In: M. Ioannides and E. Quak (eds.), 3D Research Challenges, Berling-Heidelberg, Springer-Verlag, pp. 119-134.

Neumüller M.; Reichinger A. (2014b): From Stereoscopy to Tactile Photography. In: PhotoResearcher, 19, pp. 59-63.

Petrelli D.; Ciolfi L.; Van Dijk, D.; Horneker E.; Not E.; Schmidt A. (2013): Integrating Material and Digital: A New Wat for Cultural Heritage. In: Interacions, 20, pp. 58-63.

Rivola R.; Castagnetti C.; Bertacchini E.; Casagrande F. (2016): Le tecniche geomatiche a supporto dei Beni Culturali. Digitalizzazione e stampa 3D di un mosaico a tecnica bizantina a scopo documentativo e conservative. In: ArcheomaticA $\mathrm{N}^{\circ} 1$ marzo 2016, pp. 34-37.

Santopuli N.; De Crescenzio F.; Fantini M.; Persiani F., Seccia L. (2010): L'Ebe del Canova: modello digitale e sviluppi applicativi. In: ArcheomaticA, vol. 1, pp. 40-43.

Scopigno R.; Cignoni P.; Pietroni N.; Callieri M.; Dellepiane M. (2017): Digital Fabrication Techniques for Cultural Geritage: A Survey. In: Computer Graphics Forum, 36, pp. 621.

Scopigno R.; Cignoni P.; Pietroni N.; Callieri M.; Dellepiane M. (2014): Digital Fabrication Technologies for Cultural Heritage (STAR). In: R. Klein and P. Santos (eds.), Eurographic Workshp on Graphics and Cultural Heritage, Darmstadt, Eurographic Association. ISBN: 9783905674637.

Sportun S. (2014): The Future Landscape of 3D in Museums. In: N. Levent and A. Pascual-Leone (eds.), The Multisensory Museum: Cross-disciplinary Perspectives on Touch, Sound, Smell, Memory, and Space, Plymouth, Roman \& Littlefield, pp. 319-329 ISBN: 9780810895355.

Wilson P. F.; Stott J.; Warnett J. M.; Attridge A.; Smith M. P.; Williams M. A. (2017): Evaluation of touchable 3D-printed Replicas in Museums. In: Curator: The Museum Journal, 60, 4, pp. 445-465. 
The International Archives of the Photogrammetry, Remote Sensing and Spatial Information Sciences, Volume XLII-2, 2018 ISPRS TC II Mid-term Symposium “Towards Photogrammetry 2020”, 4-7 June 2018, Riva del Garda, Italy

Geomagic: https://it.3dsystems.com/software (last accessed: $3^{\text {rd }}$ April 2018)

Mudbox:

https://www.autodesk.com/products/mudbox/overview (last accessed: $3^{\text {rd }}$ April 2018)

Sculpteo: https://www.sculpteo.com/en/ (last accessed: $3^{\text {rd }}$ April 2018)

Sculpteo Multicolor Material

https://www.sculpteo.com/en/materials/multicolor-material/

(last accessed: $3^{\text {rd }}$ April 2018)

Range 7: https://www.konicaminolta.eu/en/measuringinstruments/products/3d-measurement/range-/introduction.html (last accessed: $3^{\text {rd }}$ April 2018)

\section{Range Viewer:}

https://www.konicaminolta.com/instruments/download/software /3d/rangeviewer/index.html (last accessed: $3^{\text {rd }}$ April 2018) 